\title{
Synaptotagmin-7 is a calcium sensor for facilitation at the splanchnic-chromaffin cell synapse
}

\author{
Caballero-Florán $\mathrm{RN}^{1}$, Bendahmane $\mathrm{M}^{1}$, Philippe $\mathrm{JM}^{1}$, Mohan $\mathrm{R}^{1}$, Schenk $\mathrm{NA}^{1}$, Zhang $\mathbf{S}^{1}$, Valenta $\mathrm{A}^{2}$, Sorenson $\mathrm{MJ}^{2}$, Kennedy \\ $\mathbf{R T}^{2}$, Heuser $\mathrm{JE}^{3}$, Anantharam $\mathbf{A}^{1, 凶}$, and Jenkins $\mathrm{PM}^{1,4, 凶}$ \\ ${ }^{1}$ Department of Pharmacology, University of Michigan Medical School, Ann Arbor, MI 48109-5632 \\ ${ }^{2}$ Department of Chemistry, University of Michigan, Ann Arbor, MI 48109-5632 \\ ${ }_{3}^{3}$ Section on Integrative Biophysics, National Institute of Child Health \& Human Development, National Institutes of Health, Bethesda, MD, 20817 \\ ${ }^{4}$ Department of Psychiatry, University of Michigan Medical School, Ann Arbor, MI 48109-5632
}

\begin{abstract}
The splanchnic-chromaffin cell synapse is the site at which stimulus-secretion coupling in the adrenal medulla is regulated. However, since the discovery that acetylcholine underlies chemical signaling at this synapse, attention has been disproportionately placed on postsynaptic chromaffin cell function. As a result, the determinants of $\mathrm{Ca}^{2+}$-sensing and exocytosis from splanchnic nerves remain poorly understood. This study shows, for the first time, that a ubiquitous $\mathrm{Ca}^{2+}$-binding protein, synaptotagmin-7 (Syt7) is expressed within the neurons that innervate the adrenal medulla. In synapses that lack Syt7, evoked excitatory postsynaptic currents (EPSCs) are smaller in amplitude and decay with more rapid kinetics than wild-type synapses stimulated in an identical manner. EPSCs in Syt7deficient adrenal slices also fail to facilitate, which is ordinarily a robust property of these synapses. These data are the first to implicate a role for $\mathrm{Syt} 7$ in regulating short-term synaptic plasticity in the peripheral nervous system.
\end{abstract}

synaptotagmin | chromaffin cell | synapse | synaptic facilitation | epinephrine

Correspondence and requests for materials should be addressed to arunanan@umich.edu and pjenkins@umich.edu

\section{Introduction}

The "fight-or-flight" response encapsulates a range of physiological changes that are evolutionarily designed to prepare an individual to respond to a stressor $(1,2)$. This stressor may take on the form of an external, physical threat to the organism, an emotionally charged event, or even metabolic disturbances. Although the precise response to each stressor may vary, all share some basic characteristics of sympathetic activation (3). The heart rate and strength of contraction increase as blood is directed to skeletal muscles and the brain, and away from non-exigent activities such as digestion. Respiration is facilitated, and the pupils dilate to improve vision and assess the threat. Furthermore, the body mobilizes energy stores to supplement this demanding state, via the stimulation of gluconeogenesis in the liver $(4,5)$.

A key effector of the sympathetic nervous system and the "fight or flight" response is the adrenal medulla (3). Secretion from the adrenal medulla is dependent on input from preganglionic, sympathetic fibers which pass into the gland via the splanchnic nerves $(6,7)$. The fibers terminate on adrenomedullary chromaffin cells which synthesize and store catecholamines (epinephrine and norepinephrine) and vasoactive peptides in dense core granules (8). Due to their experimental accessibility, a great deal is now known about the mechanisms underlying dense core granule exocytosis from chromaffin cells $(9,10)$. Much of this knowledge has been derived from experiments in dissociated cells, where pharmacological and genetic manipulations are readily executed. By comparison, a paucity of information exists on the properties of splanchnic neurons, themselves. This is remarkable, considering their essential role in regulating post-synaptic chromaffin cell release, and, more broadly, in tuning blood hormone profiles to satisfy demands imposed by environmental and metabolic stressors (11-13).

The purpose of this study was to characterize the role of one synaptic protein in particular - synaptotagmin-7 (Syt7) - in regulating exocytosis at the splanchnic-chromaffin cell synapse. Syt7 belongs to a large family of proteins, numbering 17 in total, many of which couple calcium influx to vesicle fusion (14-16). Syt7 is expressed in diverse cell-types, including chromaffin cells, in which it serves as a specialized, high affinity calcium-sensor in regulated exocytosis $(14,17-$ 22). Our interest in Syt7 at splanchnic synapses has developed as a result of recent discoveries concerning Syt7 function at central nervous system (CNS) synapses. There, Syt7 is now generally acknowledged to regulate synaptic transmission in important ways, and to be required for forms of synaptic plasticity that are driven by subtle variations in calcium levels, including asynchronous release and facilitation $(18,23-27)$.

Recent studies have demonstrated that the splanchnicchromaffin cell synapse shares features common to synapses in the CNS. It exhibits forms of short- and long-term plasticity that are regulated by variations in sympathetic nervous system activity (13). Indeed, one context in which the plasticity of these synapses is important is in response to fastinginduced hypoglycemia $(13,28)$. Nevertheless, to date, no role has been found for any synaptotagmins in splanchnic neurons, let alone Syt7.

The experiments described in this study were performed on adrenal slices obtained from wild-type (WT) animals or animals in which the Syt7 gene had been deleted (hereafter re- 
ferred to as Syt7 KO) (29). The absence of Syt7 had several readily discernible effects on splanchnic synaptic transmission, which was evoked by stimulating preganglionic input to chromaffin cells via a bipolar stimulating electrode. Specifically, evoked EPSCs in KO slices are smaller in amplitude and decayed with faster kinetics than those in WT slices. Moreover, facilitation, which is ordinarily a robust property of this synapse, was abrogated in the absence of Syt7. The magnitude of tonic or basal currents on which synchronous EPSCs ride (evoked by high frequency stimulus trains) were substantially smaller in KO synapses than in WT synapses. Despite these obvious electrophysiological differences, circulating levels of epinephrine were not different between WT and Syt7 KO animals. This suggests that under basal conditions, compensatory mechanisms must exist to sustain proper levels of catecholamine release, even in the global absence of Syt7.

In sum, we demonstrate here that Syt7 is indeed expressed within the splanchnic neurons which innervate the adrenal medulla, and plays a significant role in evoked release and in facilitation at their nerve terminals. Thus, our data provide the first indication of a role of Syt7 in regulating short-term synaptic plasticity in the peripheral nervous system.

\section{Materials and Methods}

Animals Litters of adult male and female Syt $7^{-/}$(gift of Dr. Joel Swanson; (29)) and Syt7 ${ }^{+/+}$(from a C57BL/6J background and obtained from Jackson Labs, Bar Harbor, ME) were used in these studies $(17,29)$. Animals were group housed ( 2 to 5 per ventilated cage) with $24 \mathrm{hr}(12 / 12$ dark/light cycle) access to food and water. All animal procedures and experiments were conducted in accordance with the University of Michigan Institutional Animal Care and Use Committee. No randomization was performed to allocate subjects in the study

In Vitro Electrophysiology Recordings and Analysis 3-4month-old animals (male and female; 18 to $25 \mathrm{~g}$ ) were gas anesthetized using an isoflurane drop jar technique and sacrificed by guillotine decapitation (all procedures are in accordance with approved UM IACAC protocol PRO000009265). Chromaffin cells are responsible for releasing catecholamines in response to stress, including hypoxia. Hence, isoflurane is used to induce a faster loss of consciousness compared to $\mathrm{CO}_{2}$ euthanasia ( $30 \mathrm{~s}$ to 1 minute versus several minutes) and reduce animal stress.

Adrenal glands were then quickly removed from the kidney and placed in ice cold $\left(4^{\circ} \mathrm{C}\right)$ slicing solution containing, in mM: $62.5 \mathrm{NaCl}, 2.5 \mathrm{KCl}, 1.25 \mathrm{KH}_{2} \mathrm{PO}_{4}, 26 \mathrm{NaHCO}_{3}, 5$ $\mathrm{MgCl}_{2}, 0.5 \mathrm{CaCl}_{2}, 20$ Glucose and 100 Sucrose (pH maintained at 7.4 by saturation with $\mathrm{O}_{2} / \mathrm{CO}_{2}, 95 / 5 \%$ respectively) with at an osmolarity of 315 milliosmolar. Glands were subsequently embedded in $3.5 \%$ agarose block solution at $4^{\circ} \mathrm{C}$. Approximately $300 \mu \mathrm{m}$ thick sections were cut with a microtome (VF-300, CompresstomeTM; Precisionary instruments, Natick MA). Slices were transferred to a stabilization chamber where they were maintained at room temperature for $60 \mathrm{~min}$ in artificial cerebrospinal fluid (ACSF) containing in $\mathrm{mM}: 125 \mathrm{NaCl}, 2.5 \mathrm{KCl}, 1.25 \mathrm{KH}_{2} \mathrm{PO}_{4}, 26 \mathrm{NaHCO}_{3}$, $1 \mathrm{MgCl}_{2}, 2 \mathrm{CaCl}_{2}$ and 20 Glucose, pH 7.4 (with 95\% $\mathrm{O}_{2}$ and $5 \% \mathrm{CO}_{2}$ bubbling through the solution, $300 \mathrm{mOsm}$ ). Then individual slices were transferred to the microscope to the recording chamber ( $300 \mu \mathrm{L}$ volume) continuously superfused with ACSF (1-2 $\mathrm{mL} / \mathrm{min})$ at room temperature.

The adrenal gland was visualized at in the microscope (Nikon Eclipse FN-1) at X10 to determine the recording and stimulation areas. The processes of preganglionic neurons were activated using a focal stimulating FHC tungsten metal bipolar electrode (2-3 M $\Omega$ ). The electrode was placed in the border between the adrenal cortex and the adrenal medulla around $50-100 \mu \mathrm{m}$ away from the recording electrode. Recording micropipettes were pulled (P-97; Sutter Instruments, Novato, CA) from borosilicate glass capillaries (1.5 mm O.D.; Harvard Apparatus, Holliston, MA) for a final resistance of 3-6 M $\Omega$. Pipettes were filled with a cesium-based internal solution of the composition in $\mathrm{mM}$ : $135 \mathrm{CsCl}, 4 \mathrm{NaCl}$, 0.4 GTP, $2 \mathrm{Mg}$-ATP, $0.5 \mathrm{CaCl}_{2}, 5$ EGTA and 10 HEPES $\mathrm{pH}$ 7.25 - 7.3 (290 mOsm). Currents were recorded with Axon Instruments, Multiclamp 700B (Axon Instruments, Union City, CA), low pass filtered at $2 \mathrm{kHz}$. Chromaffin cells in medullary slices were identified using a Nikon Eclipse FN1 microscope with a X40 water-immersion objective and a DAGE-MTI IR-1000 video camera. Whole-cell recordings (more than $8 \mathrm{G} \Omega$ before break-in) were obtained in voltageclamp configuration, acquired at $2 \mathrm{kHz}$ fixing the voltage at $-20 \mathrm{mV}$. Series resistance was monitored throughout the experiment and experiments were aborted if changes greater than $20 \%$ occurred. The cells were chosen according to the access resistance and visual examination of their membranes. The EPSCs were evoked by stimulating the preganglionic input at $0.1 \mathrm{~Hz}$ and were distinguished by their allor-none response to presynaptic stimulation and fast kinetics $(11,13,30)$. Once a "synapse" was identified, pre-ganglionic input was stimulated at $10-30 \mathrm{mV}$ intensity $(0.5 \mathrm{~ms}$ pulse duration) every 15 seconds at intervals of 60, 100, 200 and $500 \mathrm{~ms}$ or during high frequency trains $(20 \mathrm{~Hz})$. Stimulation waveforms were introduced via a Grass S48 stimulator (Quincy, MA) that was triggered using Clampex9 software.

Paired-pulse ratios (PPRs) of EPSCs (2 - 4 events per cell) were calculated by dividing the amplitude of the second EPSC by that of the first (PPR = EPSC2/EPSC 1$)$. For experiments involving the application of hexamethonium (hexane1,6-bis (trimethylammonium bromide)) a non-depolarizing nicotinic receptor (nAChR) antagonist at concentration of $100 \mu \mathrm{M}$ was added to the bath, and stimulation was conducted at $0.1 \mathrm{~Hz}$ (unless otherwise indicated) the slice was perfused with ACSF (1-2 $\mathrm{mL} / \mathrm{min})$ in presence of the drug for $5 \mathrm{~min}$ utes before washout and for before $5 \mathrm{~min}$ to obtain a baseline response. Peak current amplitudes were searched identified manually using pCLAMP 10 (Molecular Devices, San Jose, $\mathrm{CA}$ ), and visually monitored to exclude the erroneous noise. The current response was fit by a single exponential equation to obtain the time constant (tau) of decay. Basal current (during high frequency stimulation) is measured as the difference 
between the sustained currents reached during the train and the overall baseline current of the record (26). Data in all figures represent the mean \pm standard error of the mean (SEM). Unless stated otherwise, statistical significance was assessed by unpaired two-tailed Student's t-test, or one-way ANOVA followed by Tukey's post-hoc test.

Reverse transcription and quantitative PCR Reverse transcription was performed on mouse adrenal medullas dissected from adrenal glands and homogenized, as published in(17). Adrenal medullas from two animals in each WT and Syt7 KO group are considered as one experiment. Specifically, four adrenal medullas from two animals were homogenized in one 1.5-ml Eppendorf tube on ice for 45 seconds with motorized pestle mixer (Argos Technologies, Inc, Vernon Hills, IL). More than three experiments were performed for each target. RNeasy Mini (Qiagen, Valencia, CA) was used to isolate the RNAs. The first strand cDNA synthesis was performed with $400 \mathrm{ng}$ of RNAs using the qScript cDNA SuperMix kit (Quanta Biosciences, Beverly, MA). The reverse transcription product was kept at $-20^{\circ} \mathrm{C}$ until qPCR was performed. qPCR primers for the target genes were designed with online tools (GenScript PCR Primer Design and NCBI primer designing tool). The forward $(\mathrm{Fw})$ and reverse $(\mathrm{Rv})$ primer sequences are as follows (listed 5' to 3'):

\section{TH Fw GCGCCGGAAGCTGATTGCAG}

\section{TH Rv CCGGCAGGCATGGGTAGCAT}

\section{a3 Fw GCCGCTGTCCATGCTGATGC}

\section{a3 Rv ACAGGCGGTGCTCAGCTTCC}

\section{$\beta 4$ Fw GGCCTGGAACAGCTCCTGCT}

\section{$\beta 4$ Rv AGCCACTGGATGCTGCCGTT}

Immunofluorescence 3-4 month-old mice (male and female) were administered a ketamine/xylazine mixture $(80 \mathrm{mg} / \mathrm{kg}$ body weight ketamine and $10 \mathrm{mg} / \mathrm{kg}$ xylazine) via intraperitoneal injection. The mice were perfused by cardiac perfusion of PBS followed by 4\% paraformaldehyde (PFA). Adrenal glands were immediately removed and fat and connective tissues surrounding the glands were trimmed off. Glands were then kept in 4\% PFA for 2 hours and then immersed in series of sucrose solutions $(10 \%, 15 \%$ and $30 \%$ in 1x PBS) until the tissues sink. After that, they were carefully transferred to a mold containing OCT media without any bubbles and immediately frozen using dry ice. Slices were then sectioned in a cryostat. Upon staining, adrenal gland slices were fixed with 4\% PFA for 10 minutes, and washed $3 \mathrm{x}$ with PBS. Following fixation, slices were permeabilized using $0.2 \%$ triton X-100 in PBS for 20 minutes. Slices were then blocked with 5\% BSA and $0.1 \%$ tween in TBS for one hour, before incubating with primary antibodies (rabbit anti-Syt7 (SySy, Göttingen, Germany), mouse antiTH (Sigma Aldrich, St. Louis, MO), and goat anti-ChAT (MilliporeSigma, Burlington, MA)) at a 1:400 dilution and at $4{ }^{\circ} \mathrm{C}$ overnight. On the following day, slices were washed $3 \mathrm{x}$ for 15 minutes each with TBST and incubated with secondary antibodies diluted in blocking buffer for $1 \mathrm{hr}$ at room temperature. Fluorescently conjugated secondary antibodies Alexa 488, 568, and 647 (1:250, ThermoFisher, Waltham,
MA) were used. Secondary antibodies were washed three times with TBST for 15 minutes each and mounted on glass slides with Prolong Gold.

Imaging was performed using a confocal microscope (LSM880, Zeiss, Germany) with a 63x oil immersion objective in Airyscan mode. Excitation was accomplished using 405-, 488-, 561-, and 633-nm lasers. All images were further processed in Adobe Photoshop CS6 software. Plot profiles were generated with ImageJ.

Mass spectrometry Plasma epinephrine levels were quantified using a liquid chromatography-mass spectrometry method modified from P. Song, et al. (31). In brief, 9 $\mu \mathrm{L}$ of plasma was spiked with $1 \mu \mathrm{L}$ of $12.5 \mathrm{mM}$ ascorbic acid to prevent epinephrine oxidation as well as $1 \mu \mathrm{L}$ of $1 \mu \mathrm{M}$ D6-ephinephrine for determination of extraction efficiency. Proteins were precipitated by adding $39 \mu \mathrm{L}$ of cold acetonitrile and centrifuging for $10 \mathrm{~min}$ at $12,100 \mathrm{x}$ g. 20 $\mu \mathrm{L}$ of supernatant was removed and immediately derivatized with benzoyl chloride. For the reaction, $10 \mu \mathrm{L}$ of $100 \mathrm{mM}$ sodium carbonate, $10 \mu \mathrm{L}$ of benzoyl chloride ( $2 \%$ in acetonitrile, v/v), and $10 \mu \mathrm{L}$ of sulfuric acid (1\% in $4: 1$ water/acetonitrile, $\mathrm{v} / \mathrm{v}$ ) were added sequentially, briefly vortexing between each addition. 2 Calibration standards were prepared from 0.1-50 nM in artificial cerebrospinal fluid to approximate plasma salt composition. Samples were analyzed in triplicate $(5 \mu \mathrm{L} /$ injection) on a Phenomenex Kinetex C18 column $(100 \times 2.1 \mathrm{~mm}, 1.7 \mu \mathrm{m})$ by a Vanquish UHPLC system (ThermoFisher Scientific, Gemering, Germany) and detected on a TSQ Quantum Ultra triple quadrupole mass spectrometer (Thermo Fisher Scientific, San Jose, CA) operated in multiple-reaction monitoring mode. The flowrate was 600 $\mu \mathrm{L} / \mathrm{min}$. Mobile phase A consisted of $10 \mathrm{mM}$ ammonium formate and $0.15 \%(\mathrm{v} / \mathrm{v})$ formic acid in water. Mobile phase B was pure acetonitrile. Peak integration was performed using XCalibur 3.0 software.

Enzyme-linked immunosorbent assay (ELISA) for epinephrine Adrenal glands were dissected from 3-4 monthold male mice and weighed. Glands were then lysed in 300 $\mu \mathrm{L}$ of $0.01 \mathrm{~N} \mathrm{HCl}$ and $0.15 \mathrm{mM}$ EDTA using handheld, battery-operated homogenizer. Supernatant was diluted 500 -fold and $10 \mu \mathrm{L}$ of the diluted sample was used for ELISA following the manufacturer's protocol (Epinephrine ELISA kit KA1882, Abnova, Taipei, Taiwan). Briefly, 10 $\mu \mathrm{L}$ of samples, standard and controls were loaded onto cis-diol-specific affinity-based gel plate and extracted, acylated and then converted enzymatically. $100 \mu \mathrm{L}$ of the extracted epinephrine was then transferred to a microtiter plate for competitive ELISA. Quantification was performed by measuring absorbance at $450 \mathrm{~nm}$ against the reference wavelength of $630 \mathrm{~nm}$ and analyzed from reference curve generated using known standard concentrations.

Western blotting Adrenal glands were dissected from 3 month-old mice and the cortex tissue surrounding the adrenal medulla was removed carefully using fine scissors. Adrenal medulla was then homogenized in urea-based tissue lysis buffer. Equal volume of the lysate was loaded onto 4-20\% tris-glycine mini gels (Novex, Invitrogen). Proteins were 
transferred onto a membrane and stained using Ponceau-S to check or normalize for equal protein load. The membrane was blocked with a 5\% milk solution. The blot was incubated with primary antibody (anti-TH, 1:1000, Sigma Aldrich, Catalog. No. T2928) and followed by secondary antibody incubation and then developed using ECL reagent in an imager.

Electron microscopy After anesthetizing 2-month-old mice with $2 \%$ isoflurane in $100 \% \mathrm{O}_{2}$, transcardial perfusionfixation was performed on a downdraft table equipped with a chemical waste collection system. Immediately upon cannulation of the left ventricle, perfusion was initiated with $200 \mathrm{ml}$ of $2 \%$ glutaraldehyde in an "artificial mammalian Ringer's solution" with elevated buffering capacity $(100 \mathrm{mM} \mathrm{NaCl}$, $30 \mathrm{mM}$ HEPES buffer $\mathrm{pH} 7.4$ and $2 \mathrm{mM} \mathrm{CaCl}_{2}$ ). Thereafter, adrenals were dissected from the fixed mice and maintained in this same aldehyde fixative until post-fixation. This was performed by first washing away the fixative with $100 \mathrm{mM}$ cacodylate buffer (always containing the same $2 \mathrm{mM} \mathrm{Ca}^{2+}$ to optimize membrane structure, in this and all subsequent steps, so this buffer will henceforth be termed "cacodylate$\mathrm{Ca} ")$. After this wash, the adrenals were sliced into 500um thick sections with a homemade tissue-chopper and postfixed for $30 \mathrm{~min}$ with $0.25 \% \mathrm{OsO}_{4}$ and $0.25 \%$ potassium ferrocyanide in cacodylate-Ca buffer, made fresh by mixing the two immediately before application. After washing away this post-fixative with more cacodylate-Ca buffer, the adrenals were then "mordanted" for $30 \mathrm{~min}$ with $0.5 \%$ tannic acid (Polysciences mw 1700) plus 0.5\% saponin (Mallinckrodt) again in cacodylate-Ca buffer. After washing this away with more cacodylate-Ca buffer and lowering the $\mathrm{pH}$ to 5.2 with a brief wash in acetate buffer, the adrenals were finally "block stained" for 30min with $0.5 \%$ uranyl acetate in $\mathrm{pH} 5.2$ acetate buffer. Thereafter, the UA was washed out briefly with acetate buffer and the adrenals were dehydrated in ethanol, starting with $50 \%$ ethanol in water, on up through $75 \%$ and $95 \%$, and finally $100 \%$ ethanol for many hours or overnight. Finally the adrenal slices were embedded in Araldite 502 epoxy resin (so-called "English Araldite") by exchanging ethanol with propylene oxide for $30 \mathrm{~min}$, then with a mixture of $2 / 3$ rds epoxy and $1 / 3$ rd propylene oxide for 2 hours, and then into 100 Araldite epoxy overnight (all with continuous rotation to optimize plastic-infiltration).

After a final exchange into freshly prepared Araldite epoxy, the resin was polymerized in a $70^{\circ} \mathrm{C}$ vacuum-oven for $24-48$ hrs. Thereafter, the embedded adrenals were sectioned with a Reichert-Jung Ultracut-E ultramicrotome using a Diatome diamond knife, first as 0.5 micron "semi-thins" for viewing in the LM after staining with $1 \%$ toluidine blue and $1 \%$ sodium borate in water for $15 \mathrm{sec}$ on a hotplate, in order to choose the proper regions for examination, then further thinsectioned at $40 \mathrm{~nm}$ for the absolutely crispest membranes, at $90 \mathrm{~nm}$ for best general overviews, and at $200-250 \mathrm{~nm}$ for obtaining 3-D information about overall nerve-orientation within the adrenals. Thin sections were retrieved onto hightransmission fine-hexagonal 200-mesh copper grids (made in England by Guilder, LTD, and sold in the US by Ladd Industries, cat. no. G200HHC), after the grids were coated with a silver-thin film of Formvar and then carbon-coated with $10 \mathrm{sec}$ of evaporated carbon, for maximum specimen stability. Finally, the thin-sections were stained for $5 \mathrm{~min}$ on a drop of $1 \%$ lead citrate in a closed dish with $\mathrm{NaOH}$ pellets around to prevent $\mathrm{CO}_{2}$-precipitation of the lead, and washed with a gentle stream of water from a squirt bottle. They were examined with a standard transmission electron microscope (JEM1400 TEM) operated at 80KV and mounted with the smallest available objective aperture, for maximum contrast (and especially, for maximum removal of chromatic aberration from the quarter-micron thick sections). Images were obtained with the highest resolution digital camera available, the AMT 'BioSprint' 29 Megapixel Camera, which produces $6.5 \mathrm{k} x$ 4.5k images. The digital images thus obtained were processed with Photoshop, taking special advantage of its "high-pass" filter when very dark features happened to be located next to very light areas in the images, which made otherwise made details hard to resolve.

\section{Results}

Synaptotagmin-7 is present in preganglionic, cholinergic axons that innervate the adrenal medulla.

Chromaffin cells of the adrenal medulla are innervated by preganglionic sympathetic fibers that pass into the gland by way of the splanchnic nerves (7). An image of an adrenal section containing axons and, ostensibly, nerve terminals, in addition to chromaffin cells, is shown in Figure 1A. The section has been immunolabeled with antibodies for choline acetyltransferase (ChAT) and tyrosine hydroxylase (TH) to label ACh-producing neurons and chromaffin cells, respectively. Some axons were observed to encircle chromaffin cells as they pass through the medulla (Figure 1A). Viewed at a higher magnification in Figures 1B-C, ChAT-positive fibers display occasional varicosities in which Syt7 fluorescence is also enriched, which suggests that they are forming en passant synapses with the chromaffin cells. A region in Figure 1C (dotted black line) was subjected to a line fluorescence intensity analysis, which compared the brightness of Syt7 with that of TH and ChAT. The corresponding graph in Figure 1D shows that coincident with an increase in ChAT fluorescence, Syt7 fluorescence also increases. On the other hand, TH fluorescence is highest in areas from which ChAT is excluded.

The images referenced in Figure 1 suggest that there to be a close morphological relationship between splanchnic neurons and chromaffin cells, which is similar in form to the relationship between pre- and post-synaptic cells within the brain (7). This supposition was readily verified by electron microscopy (EM), on slices of adrenal medulla from mice that were perfusion-fixed for optimal preservation of structure (see methods). Throughout all these slices, abundant examples of vesicle-laden nerve terminals were found, with almost every single chromaffin cell showing its own synaptic contact. These contacts displayed all the features that are found in synapses throughout the CNS and PNS, including typical pre- and postsynaptic densities, striking accumula- 
A

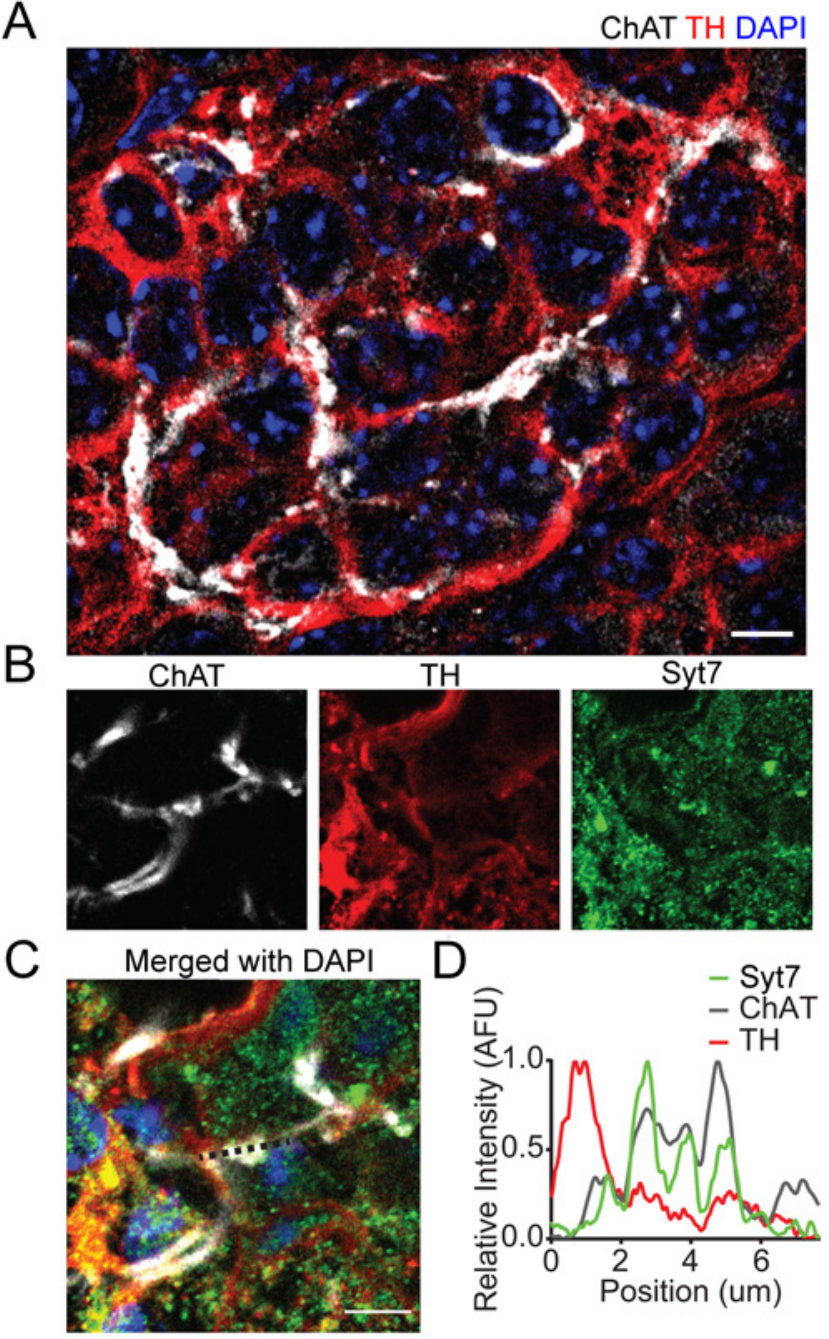

Fig. 1. Splanchnic axons envelop TH-labeled medullary chromaffin cells and form cholinergic synapses in which Syt7 is expressed. A. Representative image (of 14 sections in more than 7 independent preps) of a cholinergic synapse in the adrenal medulla of adrenal glands from adult C57BL/6J mice. Adrenal gland slices were immunostained with a marker of cholinergic neurons, choline acetyltransferase (ChAT) (white), and the postsynaptic cholinergic marker, tyrosine hydroxylase $(\mathrm{TH})(\mathrm{red})$, with DAPI as a nuclear stain. Scale bar: $20 \mu \mathrm{m}$. B. Adrenal medullae were immunostained with synaptotagmin-7 (Syt7) (green), the postsynaptic cholinergic marker tyrosine hydroxylase (TH) (red), and a marker of cholinergic neurons, choline acetyltransferase (ChAT) (white). C. Merged image of a cholinergic synapse whereby ChAT and Syt7 are co-localized along the marked region of interest (dotted line). Scale bar, $5 \mu \mathrm{m}$. D. Line fluorescence intensity analysis along line from panel $\mathrm{C}$. Plot profile demonstrating pixel intensity for each channel as a function of distance along the defined region of interest (Syt7, green; TH, red; ChAT, white).

tions of small synaptic vesicles, both round and flat, plus variable accumulations of somewhat larger dense-cored synaptic vesicles, abundant mitochondria, etc. Representative electron micrographs of such medullary synapses are shown in Figure 2. They are observed to house abundant collections of electron-lucent, pleomorphic vesicles, in addition to some dense-cored vesicles (DCVs). Based on images obtained from 6 different glands we prepared for EM, DCVs comprise only a small proportion of the total number of vesicles in these splanchnic synapses, and their numbers vary dramatically from one synapse to the next (compare DCVs in Figure
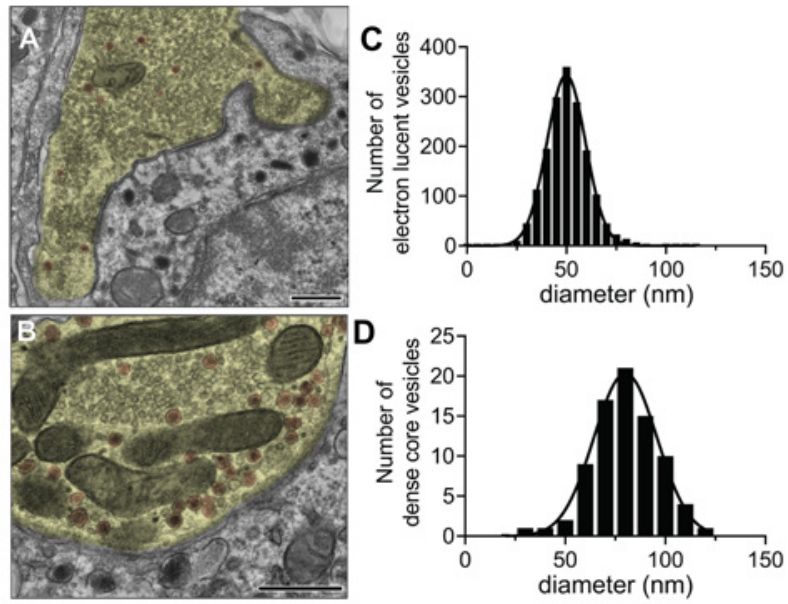

Fig. 2. Electron micrographs of splanchnic nerve processes in adrenal medullae of aldehyde-perfused C57BL/6J mice. A, B. Vesicle-filled nerve terminals (highlighted yellow), appose chromaffin cells (uncolored) across typical $25 \mathrm{~nm}$ wide synaptic clefts, bordered intermittently by pre-and postsynaptic electron-densities. The majority of synaptic vesicles are small and electron-lucent, but also present in the nerves are variable numbers of larger dense-cored vesicles (highlighted orange) demonstrably more abundant in panel B. C, D. Panels display vesicle sizemeasurements made on a random set of eight synapses out of fifty such views, displaying a mean diameter of $49.8 \pm 9.8 \mathrm{~nm}$ for the electron-lucent vesicles versus a mean diameter of $0.1 \pm 15.7 \mathrm{~nm}$ for the dense-cored vesicles (means $\pm \mathrm{SD}$ ). Bar, $0.5 \mu \mathrm{m}$.

2A vs. 2B). Likewise, the number of mitochondria varied widely from one to the next, as again can be seen by comparing Figure $2 \mathrm{~A}$ and $\mathrm{B}$. Careful vesicle size-measurements were made on these EMs and are shown in Figure 2C and D. They indicate a mean of 50nm for the electron lucent vesicles, versus a mean of $80 \mathrm{~nm}$ for the DCVs - values that are wholly consistent with previously published electron microscopic studies $(6,7)$.

Synaptotagmin-7 is a calcium sensor for exocytosis in splanchnic nerve terminals.

Having determined that Syt7 is present in the neurons that innervate the adrenal medulla, our next goal was to assess its role in splanchnic synaptic transmission. To do so, a bipolar tungsten electrode was placed at the border between the cortex and medulla in an adrenal section prepared as described in the Methods (Figure 3A). Pulses of between $10-30 \mathrm{mV}$ (0.5 ms duration) were applied to stimulate splanchnic nerve endings while recording from chromaffin cells, which were voltage-clamped in the whole-cell configuration. Excitatory postsynaptic currents (EPSCs), evoked by splanchnic stimulation, were measured in glands obtained from both WT and Syt7 KO animals (Figure 3B, C). These currents are reversibly inhibited by the nicotinic receptor antagonist, hexamethonium (Figure 3C) (13). The amplitude of evoked EPSCs (Figure 3D) is significantly smaller in slices that lack Syt7 (Figure 3E) compared to WT slices, and decay with faster kinetics (Figure 3F).

\section{Paired-pulse facilitation is eliminated in synapses lacking} Syt7.

Syt7 has been reported to function as a specialized calcium sensor that mediates synaptic facilitation in several types of synapses in the brain $(32,33)$. Accordingly, we tested 

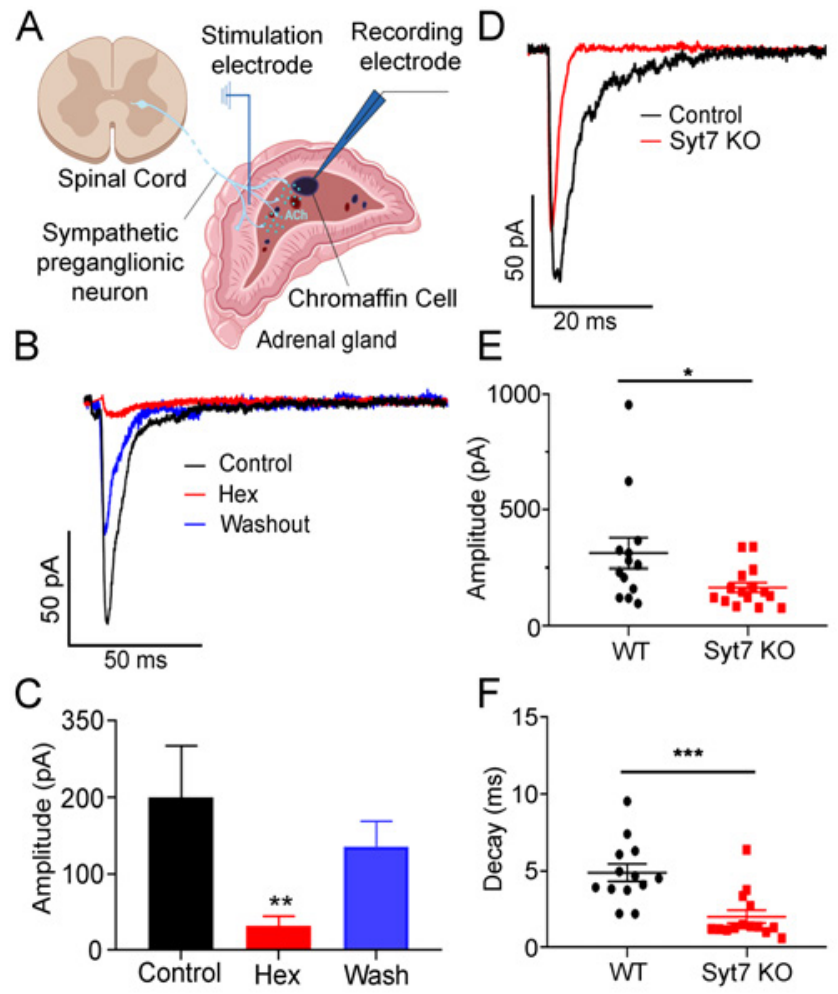

Fig. 3. Comparison of evoked EPSCs in WT and Syt7 KO synapses. A. EPSCs were evoked by stimulating preganglionic input to the adrenal medulla with a bipolar stimulating electrode. Cartoon images were created with BioRender (www.biorender.com). B. Representative EPSCs at WT synapses: Control (black), during block by Hexamethonium (Hex, red), and after Washout (blue). C. Averaged peak amplitudes \pm SEM of evoked EPSCs corresponding to conditions in B. Control vs. Hex, ${ }^{* *} p<0.01$, Kruskal-Wallis $\mathrm{H}$ test ( $\mathrm{n}=5$ slices; 3 independent preps). D. Representative EPSCs obtained chromaffin cells by stimulating WT (black) and Syt7 KO (red) axons. E. Averaged peak amplitudes \pm SEM of evoked EPSCs from WT and KO synapses. ${ }^{*} p<0.05$, Student's t-test $(n=13$ WT and $n=15$ KO slices; $>6$ independent preps). F. Average decay time constants \pm SEM of evoked EPSCs in chromaffin cells after stimulation of WT (black) and Syt7 KO (red) axons. ${ }^{* * *} p<0.001$, Student's t-test ( $n=13$ WT and $n=15$ KO slices; $>6$ independent preps).

whether it functions in a similar capacity in splanchnic nerve terminals. Data, presented in Figure 4A, show that facilitation is indeed a property of synapses within the adrenal medulla. This was demonstrated by applying two successive depolarizing pulses and calculating the paired-pulse ratio or PPR (the amplitude of the second EPSC divided by the amplitude of the first). Interstimulus intervals (ISIs) ranging from $60 \mathrm{~ms}$ to $200 \mathrm{~ms}$ consistently resulted in PPRs above 1 (Figure 4A). On the other hand, PPRs above 1 were never noted at synapses lacking Syt7, irrespective of the ISI (Figure $4 \mathrm{~A}$ ). To rule out that this was not a consequence of the first pulse releasing so much transmitter that the terminals were already partly exhausted, we reduced evoked release by lowering extracellular calcium from $2.0 \mathrm{mM}$ to $0.5 \mathrm{mM}$ (18) (Figure 4B; see also Figure S1). Even under these conditions of low release probability, facilitation was not observed in any splanchnic synapses from Syt7-deficient mice.

A reduction in the EPSCs evoked by stimulating splanchnic input to chromaffin cells could be due, in theory, to a reduction in postsynaptic nicotinic receptor expression. We previ-
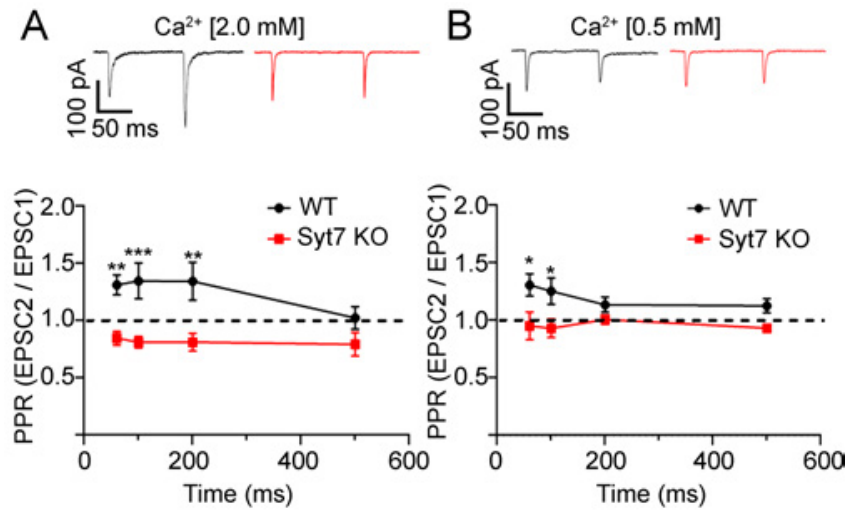

Fig. 4. Facilitation is absent in Syt7 KO adrenal medulla slices. A. Representative traces (top) and averaged paired-pulse ratio (PPRs) \pm SEM from evoked EPSCs at different interstimulus intervals (ISIs). PPRs at WT (black) and Syt7 KO (red) synapses are significantly different at ISIs of 60,100 and $200 \mathrm{~ms}$ intervals but not at $500 \mathrm{~ms} .{ }^{* *} p<0.01,{ }^{* * *} p<0.001$, Two-way ANOVA ( $n=13$ WT and $n=13 \mathrm{KO}$ slices; $>6$ independent preps). B. Experiments were repeated at low extracellular $\mathrm{Ca}^{2+}(0.5 \mathrm{mM})$ and PPRs calculated as in A. ${ }^{*} p<0.05$, Two-way ANOVA $(n=12$ WT and $n=13 \mathrm{KO}$ slices; $>6$ independent preps).

ously showed that nicotinic currents in dissociated WT and Syt7 KO chromaffin cells, evoked by local perfusion of ACh, are not discernibly different, rendering such a possibility unlikely (Bendahmane et al., J Neurochem, 2020). Moreover, mRNA levels for $\alpha 3$ and $\mathbf{4}$ subunits - which form the channel through which the majority of synaptic current activated by ACh passes (34-36) - are essentially unchanged (Figure S2).

An asynchronous mode of release was not evident at the splanchnic-chromaffin cell synapse Because facilitation and asynchronous release both rely on the same submicromolar $\mathrm{Ca}^{2+}$ signal, reflect a transient increase in release probability, and exhibit similar decay kinetics, it follows that they may utilize the same mechanism (14). In fact, Syt7 has been shown to mediate either facilitation (18), asynchronous release $(23,25)$, or both $(32)$, in various locations in the brain. Before addressing whether Syt7 has a role in mediating asynchronous release in the adrenal gland, it was first necessary to determine whether this mode of transmission is even a feature of the splanchnic synapse. In WT adrenal slices, splanchnic input to chromaffin cells was stimulated with a single depolarizing pulse via a bipolar electrode, at voltages ranging from $30-150 \mathrm{mV}$. Asynchronous EPSCs, should they occur, would appear as a delayed, or slower component of the evoked current that is not time-locked to stimulus application $(14,37)$. No events that fit that definition were evident in multiple trials performed at splanchnic synapses (Figure S3).

\section{High frequency trains result in facilitating EPSCs in WT but not Syt7 KO synapses.}

Chromaffin cells of the adrenal medulla vary dramatically in the rate at which they fire $(12,38)$. The variation in firing rate, in turn, may reflect the changing demands placed on them as effectors of the sympathetic stress response (39). In experimental paradigms mimicking strong sympathetic activation of chromaffin cell secretion, splanchnic input has been stimulated at rates that ranged from $10-20 \mathrm{~Hz}(30,38,40)$. We sought to determine whether the splanchnic synapse fa- 


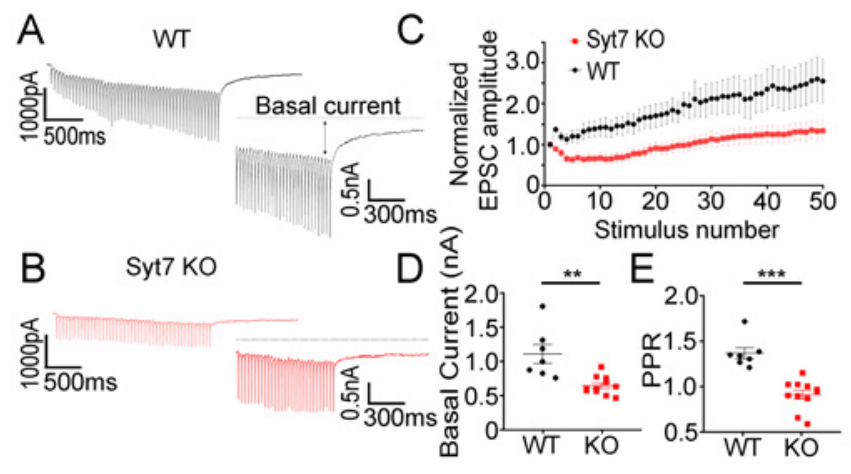

Fig. 5. Basal current is reduced at Syt7 KO synapses.A, B. Synaptic responses to $20 \mathrm{~Hz}$ stimulation recorded from WT (black) and Syt7 KO (red) preparations. Expanded traces show the basal current. C. Summary graph of individual EPSC amplitudes normalized to the first EPSC amplitude during a train (WT in black and Syt7 KO in red). D. Summary graph of the average basal current amplitudes \pm SEM. ${ }^{* *} p<0.01$, Student's t-test ( $n=7$ WT and $n=11$ KO slices; $>4$ independent preps). E. Average PPRs \pm SEM calculated by dividing the second EPSC in the train by the first. ${ }^{* * *} p<0.001$, Student's t-test $(n=7$ WT and $n=11$ KO slices; $>4$ independent preps).

cilitates even at these high firing rates, or whether it might undergo depression. An exemplar current trace in which the splanchnic input is stimulated at $20 \mathrm{~Hz}$ for 2.5 is shown in Figure 5A. WT synapses facilitate over the time course of stimulation, with successive EPSCs being larger than the one which preceded them. This is also evident in the graph shown Figure 5C, in which normalized EPSC amplitudes from several independent trials ( $\mathrm{n}=7 \mathrm{WT}$; $\mathrm{n}=9$ Syt7 KO) are plotted against stimulus number. Syt7 KO synapses, on the other hand, fail to facilitate, even at these high stimulation frequencies (Figures 5B, C, and E).

A second notable difference between WT and KO synapses, is that the basal or tonic current, on top of which synchronous EPSCs ride, is markedly smaller in the absence of Syt7 (Figure 5D). The interpretation of the basal current is not straightforward. It has been attributed previously to an asynchronous component of release (26). However, the fact that asynchronous currents were not observed at splanchnic synapses (Figure S3) would argue against this interpretation.

Epinephrine levels in blood plasma and in the adrenal medulla are normal in the Syt7 KO. Syt7 has a role in exocytosis in the presynaptic neurons that innervate postsynaptic chromaffin cells (this study) and also in postsynaptic chromaffin cells proper $(17,41,42)$. It might be reasonably inferred from these observations that basal epinephrine output ought to be disrupted animals that lack Syt7. To test the validity of this idea, plasma epinephrine was measured by LC-MS (31) in whole-body blood collected from WT and Syt7 KO animals. Surprisingly, no significant difference in plasma epinephrine concentration was noted between the two groups (Figure 6A). We next investigated the possibility that tissue epinephrine content is elevated in the Syt7 KO as a means to compensate for the overall reduction in release efficacy in the adrenomedullary system. However, no significant change in the expression level of tyrosine hydroxylase transcript (Figure S3), tyrosine hydroxylase protein (Figure S4), or epinephrine content (Figures 6B-6D) was detected in tis- sue harvested from WT and Syt7 KO animals.

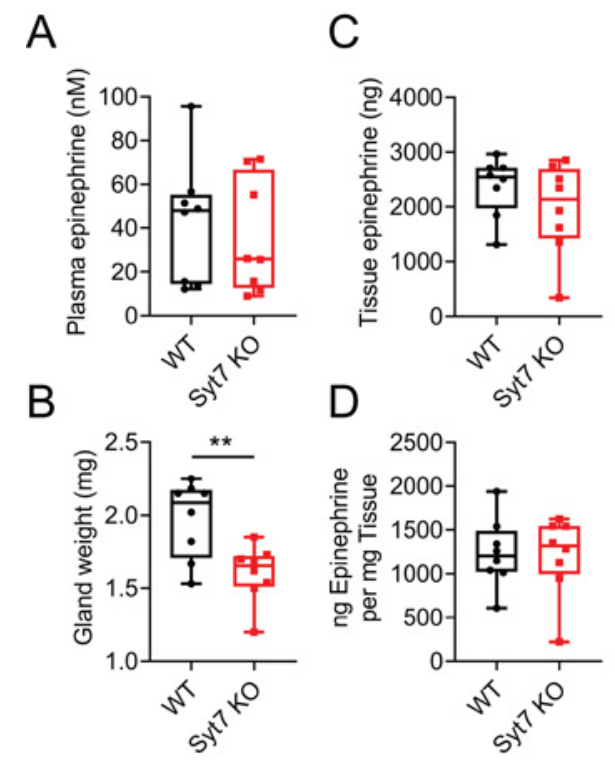

Fig. 6. Epinephrine content in blood plasma and adrenal lysates. A. LC-MS analysis for epinephrine was performed on whole-body blood plasma (see Methods). Average epinephrine concentrations are shown. No significant difference between groups ( $n=8$ for $W T ; n=8$ for $K O$ ) was observed (Student's t-test). B. Freshly dissected adrenal glands from WT $(n=8)$ and $K O(n=8)$ animals were weighed. Average weight of glands is shown; the difference in values is statistically significant. ${ }^{* *} p<0.01$, Student's t-test. C - D. Tissue epinephrine was measured using an ELISA assay. Average epinephrine content and epinephrine content per gland weight are shown. Differences in their values are not statistically significant (Student's t-test).

\section{Discussion}

The splanchnic-chromaffin cell synapse is the site at which stimulus-secretion coupling in the adrenal medulla is regulated. However, since the discovery that ACh underlies chemical signaling at this synapse (43), attention has been disproportionately placed on identifying mechanisms of postsynaptic chromaffin cell function (9). As a result, the molecular determinants of $\mathrm{Ca}^{2+}$-sensing and synaptic release at splanchnic nerve endings are largely unexplored. In this study, we show for the first time that a ubiquitous $\mathrm{Ca}^{2+}$-binding protein, synaptotagmin is expressed within the neurons that innervate the adrenal medulla. These data are the first to implicate a role for any synaptotagmin, let alone Syt7, in regulating neurotransmission at these synapses.

As is the case in the CNS, the functions of Syt7 in the periphery are closely tied to a property that sets it apart from the other $\mathrm{Ca}^{2+}$-binding members of the synaptotagmin family - its exceptionally high affinity for $\mathrm{Ca}^{2+}(44,45)$. What situations might demand such a $\mathrm{Ca}^{2+}$ sensor? Although not measured in this study, it is known that action potentials cause brief, large $\mathrm{Ca}^{2+}$ elevations in the immediate vicinity of opened voltage-gated $\mathrm{Ca}^{2+}$ channels at synaptic terminals - termed $\mathrm{Ca}^{2+}$ nanodomains (46-48). With inactivation of $\mathrm{Ca}^{2+}$ channels, and subsequent collapse of nanodomains, a modest amount (possibly submicromolar) of residual free $\mathrm{Ca}^{2+}$ persists in the presynaptic terminal before being buffered, sequestered into intracellular organelles, or extruded (49). It is in this setting of residual $\mathrm{Ca}^{2+}$, which is 
insufficient to activate low affinity sensors such as Syt-1 or Syt-2, that a requirement for Syt7 is manifested.

Two closely related forms of synaptic plasticity are thought to rely on submicromolar $\mathrm{Ca}^{2+}$ - asynchronous release and facilitation $(50,51)$. While our experiments did not uncover evidence for asynchronous release, facilitation is clearly a robust property of the splanchnic-chromaffin cell synapse (Figure 4). And, consistent with published studies in central synapses $(18,32)$, facilitation is abolished in the absence of Syt7, whether it is driven by a pair of closely-spaced depolarizing pulses, or a high frequency stimulus train.

WT and Syt7 KO synapses are not only different with respect to the synchronous component of the evoked EPSCs. The basal current, on top of which synchronous EPSCs ride, was also substantially reduced in synapses that lacked Syt7. Although basal current has frequently been attributed to an asynchronous component of release (i.e., where secretion is not time-locked to the arrival of an action potential; (26)), its origins at the splanchnic-chromaffin cell synapse are not immediately obvious. No evidence was found here for delayed or slow release of neurotransmitter that persists after the end of a single action potential (see Figure S3), which in principle, could account for the basal current. Thus, basal current is more likely attributable to other sources such as noncanonical (e.g., GPCR-dependent), slow postsynaptic currents. Splanchnic neurons are also known to house and secrete a multitude of peptide cargos (12). We cannot yet account for the various ways, subtle or otherwise, in which peptidergic neurotransmission contributes to the phenomena measured here.

Overall, this study provides strong evidence that basic functions of synaptic operation depend on Syt7, including a form of synaptic plasticity termed facilitation. It has been suggested that facilitating synapses function as high pass filters, encoding information in high firing rates that greatly enhance effects on postsynaptic cells (52). However, the physiological role of facilitation has remained elusive. In the context of the sympatho-adrenal system, facilitation may have a role in amplifying epinephrine discharge from chromaffin cells during conditions that increase sympathetic tone, including hypoglycemia $(13,53)$. The resulting increase in circulating epinephrine would then be expected to increase blood glucose via multiple metabolic pathways $(13,53,54)$. Our data show that in Syt7 KO animals fed ad libitum, epinephrine content in the adrenal medulla, as well as in the blood, are not different from WT animals (Figure 6). However, a hypothesis, which future studies should test, is that regulated physiological responses to metabolic stressors (e.g., fasting) require release driven by splanchnic Syt7. Such studies may have to wait until Syt7 expression can be abrogated solely in the periphery, and in a tissue specific-manner. In fact, tissuespecific deletion of Syt7 will be necessary to definitively disentangle its functions in controlling CNS drive of the sympathetic nervous system, from pre- and post-synaptic functions of Syt7 in the adrenal medulla. While these sorts of efforts will not be trivial, the data presented here encourage deeper investigations into the molecular mechanisms of release at these and other autonomic synapses about which very little is known.

\section{ACKNOWLEDGEMENTS}

A.A. is supported by NIH grant R01 GM111997. R.T.K. is supported by NIH grant R01 EB003320. J.M.P. has been supported by a Pharmacological Sciences Training Program (T32GM007767) fellowship and is currently supported by a Charles W. Edmunds Predoctoral Fellowship (from the University of Michigan, Department of Pharmacology)

\section{Bibliography}

1. D. S. Goldstein. Adrenal responses to stress. Cell Mol Neurobiol, 30(8):1433-40, 2010. ISSN 1573-6830 (Electronic) 0272-4340 (Linking). doi: 10.1007/s10571-010-9606-9.

2. D. S. Goldstein and I. J. Kopin. Evolution of concepts of stress. Stress, 10(2):109-20, 2007. ISSN 1025-3890 (Print) 1025-3890 (Linking). doi: 10.1080/10253890701288935.

3. W. B. Cannon. The adrenal medulla. Bull N Y Acad Med, 16(1):3-13, 1940. ISSN 00287091 (Print) 0028-7091 (Linking).

4. L. K. McCorry. Physiology of the autonomic nervous system. Am J Pharm Educ, 71(4):78, 2007. ISSN 1553-6467 (Electronic) 0002-9459 (Linking). doi: 10.5688/aj710478.

5. A. W. Tank and D. Lee Wong. Peripheral and central effects of circulating catecholamines. Compr Physiol, 5(1):1-15, 2015. ISSN 2040-4603 (Electronic) 2040-4603 (Linking). doi: $10.1002 /$ cphy.c140007.

6. E. De Robertis and A. V. Ferreira. Submicroscopic changes of the nerve endings in the adrenal medulla after stimulation of the splanchnic nerve. J Biophys Biochem Cytol, 3(4): 611-4, 1957. ISSN 0095-9901 (Print) 0095-9901 (Linking). doi: 10.1083/jcb.3.4.611.

7. O. Grynszpan-Winograd. Adrenaline and noradrenaline cells in the adrenal medulla of the hamster: a morphological study of their innervation. J Neurocytol, 3(3):341-61, 1974. ISSN 0300-4864 (Print) 0300-4864 (Linking). doi: 10.1007/bf01097918.

8. S. W. Carmichael and H. Winkler. The adrenal chromaffin cell. Sci Am, 253(2):40-9, 1985. ISSN 0036-8733 (Print) 0036-8733 (Linking).

9. A. Anantharam and A. J. B. Kreutzberger. Unraveling the mechanisms of calcium-dependent secretion. J Gen Physiol, 151(4):417-434, 2019. ISSN 1540-7748 (Electronic) 0022-1295 (Linking). doi: 10.1085/jgp.201812298.

10. Marie France Bader, Ronald W. Holz, K. O. N. O. Kumakura, and N. I. C. O. Vitale. Exocytosis: The chromaffin cell as a model system. Annals of the New York Academy of Sciences, 971(1):178-183, 2002.

11. J. G. Barbara and K. Takeda. Quantal release at a neuronal nicotinic synapse from rat adrenal gland. Proc Natl Acad Sci U S A, 93(18):9905-9, 1996. ISSN 0027-8424 (Print) 0027-8424 (Linking). doi: 10.1073/pnas.93.18.9905.

12. N. C. Guerineau. Cholinergic and peptidergic neurotransmission in the adrenal medulla: A dynamic control of stimulus-secretion coupling. IUBMB Life, 2019. ISSN 1521-6551 (Electronic) 1521-6543 (Linking). doi: 10.1002/iub.2117.

13. M. Wang, Q. Wang, and M. D. Whim. Fasting induces a form of autonomic synaptic plasticity that prevents hypoglycemia. Proc Natl Acad Sci U S A, 113(21):E3029-38, 2016. ISSN 1091-6490 (Electronic) 0027-8424 (Linking). doi: 10.1073/pnas.1517275113.

14. D. D. MacDougall, Z. Lin, N. L. Chon, S. L. Jackman, H. Lin, J. D. Knight, and A. Anantharam. The high-affinity calcium sensor synaptotagmin-7 serves multiple roles in regulated exocytosis. J Gen Physiol, 150(6):783-807, 2018. ISSN 1540-7748 (Electronic) 0022-1295 (Linking). doi: 10.1085/jgp.201711944.

15. G. Schiavo, S. L. Osborne, and J. G. Sgouros. Synaptotagmins: more isoforms than functions? Biochem Biophys Res Commun, 248(1):1-8, 1998. ISSN 0006-291X (Print) 0006291X (Linking). doi: 10.1006/bbrc.1998.8527.

16. S. Sugita, O. H. Shin, W. Han, Y. Lao, and T. C. Sudhof. Synaptotagmins form a hierarchy of exocytotic ca(2+) sensors with distinct ca(2+) affinities. EMBO J, 21(3):270-80, 2002. ISSN 0261-4189 (Print) 0261-4189 (Linking). doi: 10.1093/emboj/21.3.270.

17. M. Bendahmane, A. Morales, A. J. B. Kreutzberger, N. A. Schenk, R. Mohan, S. Bakshi, J. M. Philippe, S. Zhang, V. Kiessling, L. K. Tamm, D. R. Giovannucci, P. M. Jenkins, and A. Anantharam. Synaptotagmin-7 enhances calcium-sensing of chromaffin cell granules and slows discharge of granule cargos. J Neurochem, 2020. ISSN 1471-4159 (Electronic) 0022-3042 (Linking). doi: 10.1111/jnc.14986.

18. S. L. Jackman, J. Turecek, J. E. Belinsky, and W. G. Regehr. The calcium sensor synaptotagmin 7 is required for synaptic facilitation. Nature, 529(7584):88-91, 2016. ISSN 14764687 (Electronic) 0028-0836 (Linking). doi: 10.1038/nature16507.

19. I. Martinez, S. Chakrabarti, T. Hellevik, J. Morehead, K. Fowler, and N. W. Andrews. Synaptotagmin vii regulates $\mathrm{ca}(2+)$-dependent exocytosis of lysosomes in fibroblasts. J Cell Biol, 148(6):1141-49, 2000. ISSN 0021-9525 (Print) 0021-9525 (Linking).

20. S. Sugita, W. Han, S. Butz, X. Liu, R. Fernandez-Chacon, Y. Lao, and T. C. Sudhof. Synaptotagmin vii as a plasma membrane ca(2+) sensor in exocytosis. Neuron, 30(2):459-73, 2001. ISSN 0896-6273 (Print) 0896-6273 (Linking). doi: 10.1016/s0896-6273(01)00290-2.

21. P. Wang, M. C. Chicka, A. Bhalla, D. A. Richards, and E. R. Chapman. Synaptotagmin vii is targeted to secretory organelles in pc12 cells, where it functions as a high-affinity calcium sensor. Mol Cell Biol, 25(19):8693-702, 2005. ISSN 0270-7306 (Print) 0270-7306 (Linking). doi: 10.1128/MCB.25.19.8693-8702.2005.

22. Z. Zhang, Y. Wu, Z. Wang, F. M. Dunning, J. Rehfuss, D. Ramanan, E. R. Chapman, and M. B. Jackson. Release mode of large and small dense-core vesicles specified by different synaptotagmin isoforms in pc12 cells. Mol Biol Cell, 22(13):2324-36, 2011. ISSN 19394586 (Electronic) 1059-1524 (Linking). doi: 10.1091/mbc.E11-02-0159.

23. T. Bacaj, D. Wu, X. Yang, W. Morishita, P. Zhou, W. Xu, R. C. Malenka, and T. C. Sudhof. Synaptotagmin-1 and synaptotagmin-7 trigger synchronous and asynchronous phases of neurotransmitter release. Neuron, 80(4):947-59, 2013. ISSN 1097-4199 (Electronic) 08966273 (Linking). doi: 10.1016/j.neuron.2013.10.026.

24. H. Liu, H. Bai, E. Hui, L. Yang, C. S. Evans, Z. Wang, S. E. Kwon, and E. R. Chapman. 
Synaptotagmin 7 functions as a ca2+-sensor for synaptic vesicle replenishment. Elife, 3 : e01524, 2014. ISSN 2050-084X (Electronic) 2050-084X (Linking). doi: 10.7554/eLife.01524.

25. F. Luo, T. Bacaj, and T. C. Sudhof. Synaptotagmin-7 is essential for ca2+-triggered delayed asynchronous release but not for ca2+-dependent vesicle priming in retinal ribbon synapses. J Neurosci, 35(31):11024-33, 2015. ISSN 1529-2401 (Electronic) 0270-6474 (Linking). doi: 10.1523/JNEUROSCI.0759-15.2015.

26. F. Luo and T. C. Sudhof. Synaptotagmin-7-mediated asynchronous release boosts highfidelity synchronous transmission at a central synapse. Neuron, 94(4):826-839 e3, 2017. ISSN 1097-4199 (Electronic) 0896-6273 (Linking). doi: 10.1016/j.neuron.2017.04.020.

27. J. Turecek, S. L. Jackman, and W. G. Regehr. Synaptotagmin 7 confers frequency invariance onto specialized depressing synapses. Nature, 551(7681):503-506, 2017. ISSN 1476-4687 (Electronic) 0028-0836 (Linking). doi: 10.1038/nature24474.

28. R. W. Holz and A. Anantharam. Food deprivation induces presynaptic plasticity in the autonomic nervous system. Proc Natl Acad Sci U S A, 113(21):5766-7, 2016. ISSN 1091-6490 (Electronic) 0027-8424 (Linking). doi: 10.1073/pnas.1605618113.

29. S. Chakrabarti, K. S. Kobayashi, R. A. Flavell, C. B. Marks, K. Miyake, D. R. Liston, K. T. Fowler, F. S. Gorelick, and N. W. Andrews. Impaired membrane resealing and autoimmune myositis in synaptotagmin vii-deficient mice. J Cell Biol, 162(4):543-9, 2003. ISSN 00219525 (Print) 0021-9525 (Linking). doi: 10.1083/jcb.200305131.

30. J. Hill, S. A. Chan, B. Kuri, and C. Smith. Pituitary adenylate cyclase-activating peptide (pacap) recruits low voltage-activated t-type calcium influx under acute sympathetic stimulation in mouse adrenal chromaffin cells. J Biol Chem, 286(49):42459-69, 2011. ISSN 1083-351X (Electronic) 0021-9258 (Linking). doi: 10.1074/jbc.M111.289389.

31. P. Song, O. S. Mabrouk, N. D. Hershey, and R. T. Kennedy. In vivo neurochemical monitoring using benzoyl chloride derivatization and liquid chromatography-mass spectrometry. Anal Chem, 84(1):412-9, 2012. ISSN 1520-6882 (Electronic) 0003-2700 (Linking). doi: 10.1021/ ac202794q.

32. J. Turecek and W. G. Regehr. Synaptotagmin 7 mediates both facilitation and asynchronous release at granule cell synapses. J Neurosci, 38(13):3240-3251, 2018. ISSN 1529-2401 (Electronic) 0270-6474 (Linking). doi: 10.1523/JNEUROSCI.3207-17.2018.

33. J. Turecek and W. G. Regehr. Neuronal regulation of fast synaptotagmin isoforms controls the relative contributions of synchronous and asynchronous release. Neuron, 101(5):938949 e4, 2019. ISSN 1097-4199 (Electronic) 0896-6273 (Linking). doi: 10.1016/j.neuron. 2019.01.013.

34. M. Criado. Acetylcholine nicotinic receptor subtypes in chromaffin cells. Pflugers Arch, 470(1):13-20, 2018. ISSN 1432-2013 (Electronic) 0031-6768 (Linking). doi: 10.1007/ s00424-017-2050-7.

35. S. Di Angelantonio, C. Matteoni, E. Fabbretti, and A. Nistri. Molecular biology and electrophysiology of neuronal nicotinic receptors of rat chromaffin cells. Eur J Neurosci, 17(11): 2313-22, 2003. ISSN 0953-816X (Print) 0953-816X (Linking).

36. E. Tachikawa, K. Mizuma, K. Kudo, T. Kashimoto, S. Yamato, and S. Ohta. Characterization of the functional subunit combination of nicotinic acetylcholine receptors in bovine adrenal chromaffin cells. Neurosci Lett, 312(3):161-4, 2001. ISSN 0304-3940 (Print) 0304-3940 (Linking). doi: 10.1016/s0304-3940(01)02211-x.

37. Y. Goda and C. F. Stevens. Two components of transmitter release at a central synapse. Proc Natl Acad Sci U S A, 91(26):12942-6, 1994. ISSN 0027-8424 (Print) 0027-8424 (Linking). doi: 10.1073/pnas.91.26.12942.

38. A. M. de Diego, L. Gandia, and A. G. Garcia. A physiological view of the central and peripheral mechanisms that regulate the release of catecholamines at the adrenal medulla. Acta Physiol (Oxf), 192(2):287-301, 2008. ISSN 1748-1716 (Electronic) 1748-1708 (Linking). doi: 10.1111/j.1748-1716.2007.01807.x.

39. Tiberiu Fulop, Stephen Radabaugh, and Corey Smith. Activity-dependent differential transmitter release in mouse adrenal chromaffin cells. Journal of Neuroscience, 25(32):73247332, 2005.

40. K. Wolf, G. Zarkua, S. A. Chan, A. Sridhar, and C. Smith. Spatial and activity-dependent catecholamine release in rat adrenal medulla under native neuronal stimulation. Physiol Rep, 4(17), 2016. ISSN 2051-817X (Electronic) 2051-817X (Linking). doi: 10.14814/phy2. 12898 .

41. T. C. Rao, D. R. Passmore, A. R. Peleman, M. Das, E. R. Chapman, and A. Anantharam. Distinct fusion properties of synaptotagmin-1 and synaptotagmin-7 bearing dense core granules. Mol Biol Cell, 25(16):2416-27, 2014. ISSN 1939-4586 (Electronic) 1059-1524 (Linking). doi: 10.1091/mbc.E14-02-0702.

42. J. S. Schonn, A. Maximov, Y. Lao, T. C. Sudhof, and J. B. Sorensen. Synaptotagmin-1 and -7 are functionally overlapping ca2+ sensors for exocytosis in adrenal chromaffin cells. Proc Natl Acad Sci U S A, 105(10):3998-4003, 2008. ISSN 1091-6490 (Electronic) 0027-8424 (Linking). doi: 10.1073/pnas.0712373105.

43. W. W. Douglas. Stimulus-secretion coupling: the concept and clues from chromaffin and other cells. Br J Pharmacol, 34(3):451-74, 1968. ISSN 0007-1188 (Print) 0007-1188 (Linking).

44. A. Bhalla, W. C. Tucker, and E. R. Chapman. Synaptotagmin isoforms couple distinct ranges of $\mathrm{ca}_{2+}$, ba2+, and sr2+ concentration to snare-mediated membrane fusion. Mol Biol Cell, 16(10):4755-64, 2005. ISSN 1059-1524 (Print) 1059-1524 (Linking). doi: 10.1091/mbc. E05-04-0277.

45. E. Hui, J. Bai, P. Wang, M. Sugimori, R. R. Llinas, and E. R. Chapman. Three distinct kinetic groupings of the synaptotagmin family: candidate sensors for rapid and delayed exocytosis. Proc Natl Acad Sci U S A, 102(14):5210-4, 2005. ISSN 0027-8424 (Print) 0027-8424 (Linking). doi: 10.1073/pnas.0500941102.

46. P. P. Atluri and W. G. Regehr. Determinants of the time course of facilitation at the granule cell to purkinje cell synapse. J Neurosci, 16(18):5661-71, 1996. ISSN 0270-6474 (Print) 0270-6474 (Linking).

47. R. Llinas, M. Sugimori, and R. B. Silver. The concept of calcium concentration microdomains in synaptic transmission. Neuropharmacology, 34:1443-1451, 1995.

48. R. S. Zucker and A. L. Fogelson. Relationship between transmitter release and presynaptic calcium influx when calcium enters through discrete channels. Proceedings of the National Academy of Sciences of the United States of America, 83:3032-3036, 1986

49. R. S. Zucker and W. G. Regehr. Short-term synaptic plasticity. Annu Rev Physiol, 64:355-
405, 2002. ISSN 0066-4278 (Print) 0066-4278 (Linking). doi: 10.1146/annurev.physiol.64. 092501.114547.

50. P. S. Kaeser and W. G. Regehr. Molecular mechanisms for synchronous, asynchronous, and spontaneous neurotransmitter release. Annu Rev Physiol, 76:333-63, 2014. ISSN 1545-1585 (Electronic) 0066-4278 (Linking). doi: 10.1146/annurev-physiol-021113-170338.

51. R. Rahamimoff and $Y$. Yaari. Delayed release of transmitter at the frog neuromuscular junction. J Physiol, 228(1):241-57, 1973. ISSN 0022-3751 (Print) 0022-3751 (Linking). doi: 10.1113/jphysiol.1973.sp010084.

52. S. L. Jackman and W. G. Regehr. The mechanisms and functions of synaptic facilitation. Neuron, 94(3):447-464, 2017. ISSN 1097-4199 (Electronic) 0896-6273 (Linking). doi: 10 1016/j.neuron.2017.02.047.

53. Y. Ma, Q. Wang, D. Joe, M. Wang, and M. D. Whim. Recurrent hypoglycemia inhibits the counterregulatory response by suppressing adrenal activity. J Clin Invest, 128(9):38663871, 2018. ISSN 1558-8238 (Electronic) 0021-9738 (Linking). doi: 10.1172/JCI91921.

54. R. Gupta, Y. Ma, M. Wang, and M. D. Whim. Agrp-expressing adrenal chromaffin cells are involved in the sympathetic response to fasting. Endocrinology, 158(8):2572-2584, 2017. ISSN 1945-7170 (Electronic) 0013-7227 (Linking). doi: 10.1210/en.2016-1268. 


\section{Supplemental Information}

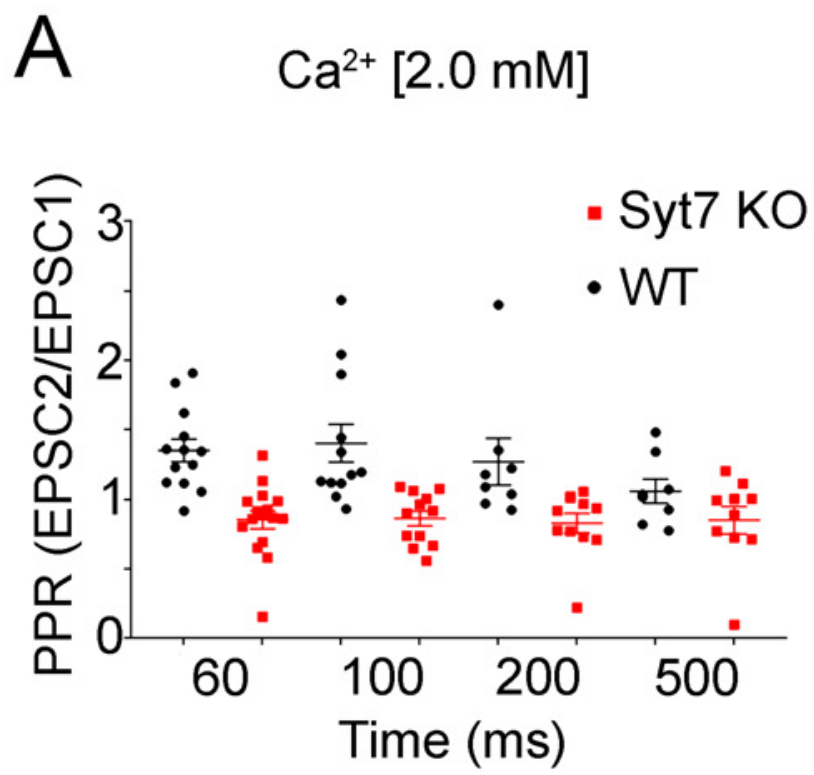

B $\quad \mathrm{Ca}^{2+}[0.5 \mathrm{mM}]$

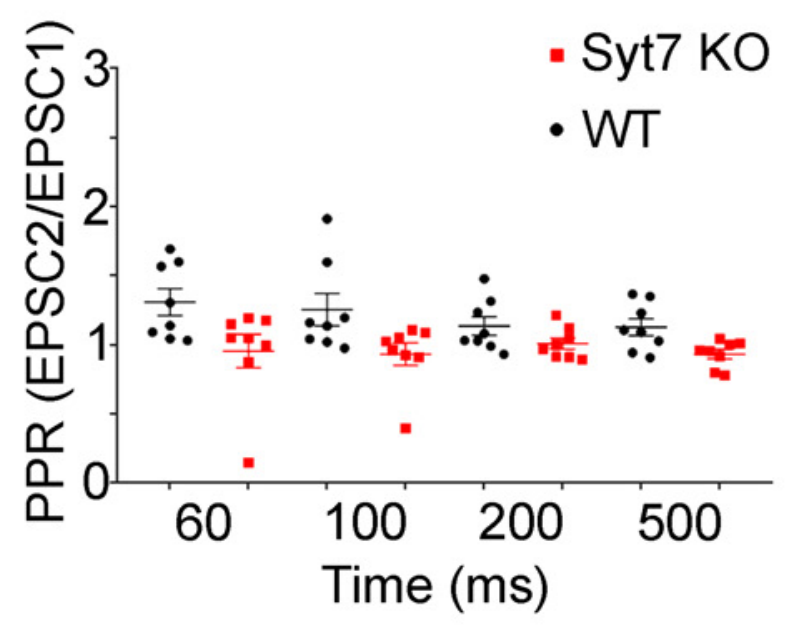

Fig. S1. PPRs calculated at normal $(2 \mathrm{mM})$ and low $(0.5 \mathrm{mM})$ extracellular $\mathrm{Ca}^{2+}$. A. PPRs calculated from evoked EPSCs at a range of interstimulus intervals $(60,100,200,500 \mathrm{~ms})$ in WT and Syt7 KO synapses in $2 \mathrm{mM}$ extracellular $\mathrm{Ca}^{2+}$. Individual data points used to generate averages in Figure 4 are shown B. PPRs calculated from evoked EPSCs, as in A, but in 0.5 mM extracellular Ca ${ }^{2+}$. 

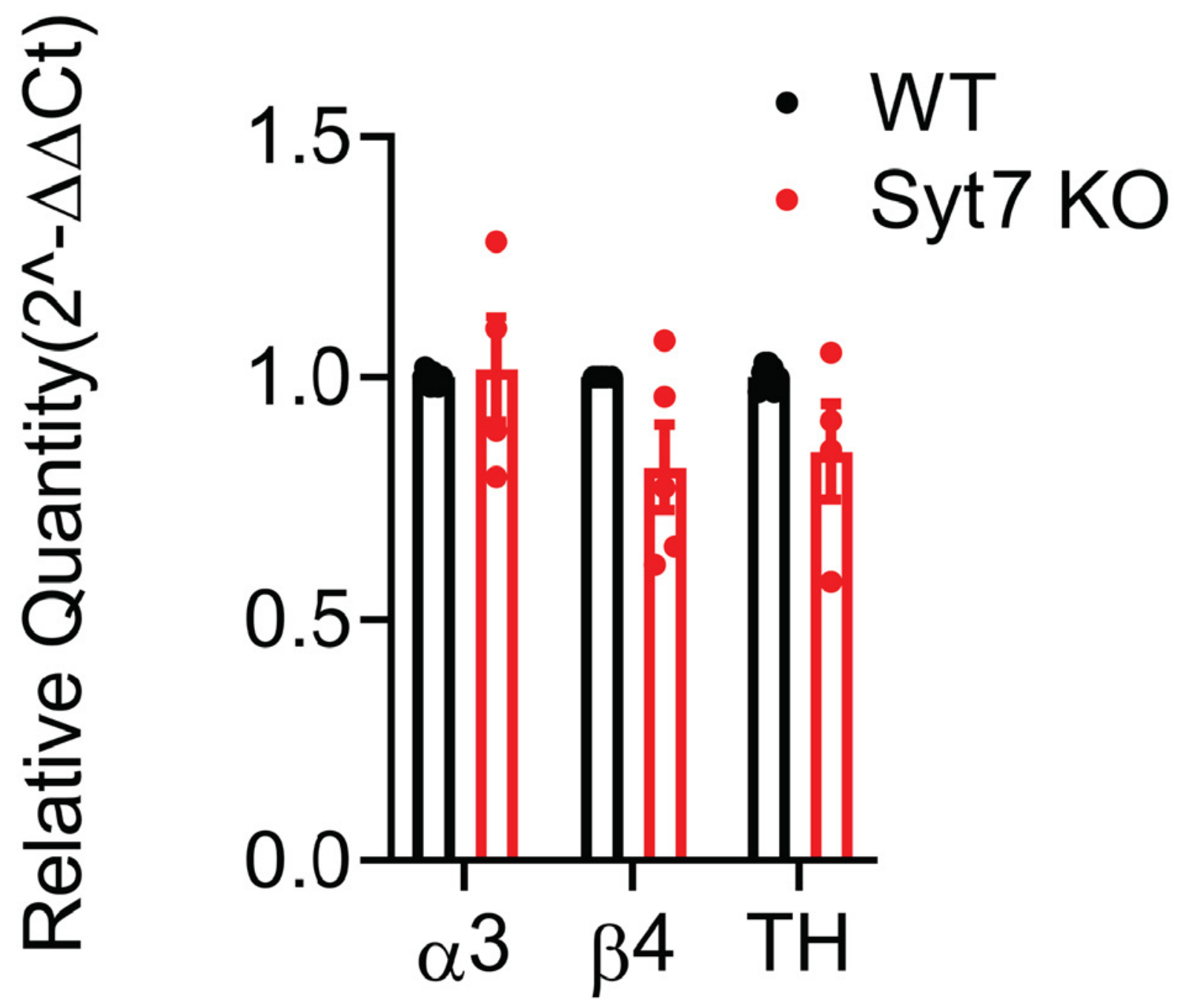

Fig. S2. Expression of $\alpha \mathbf{3}, \beta 4$, and TH transcripts in WT and Syt7 KO adrenal glands. For each individual experiment, 4 WT and $4 \mathrm{KO}$ adrenal medullas were homogenized, mRNA was extracted, and RT-qPCR was performed on the samples for $(n=6)$, NPY $(n=$ $6)$, and TH $(n=3)$. Primer sequences for qPCR can be found in Methods. No difference in transcript expression was found between WT and KO glands. $p>0.05$, Student's t-test. 


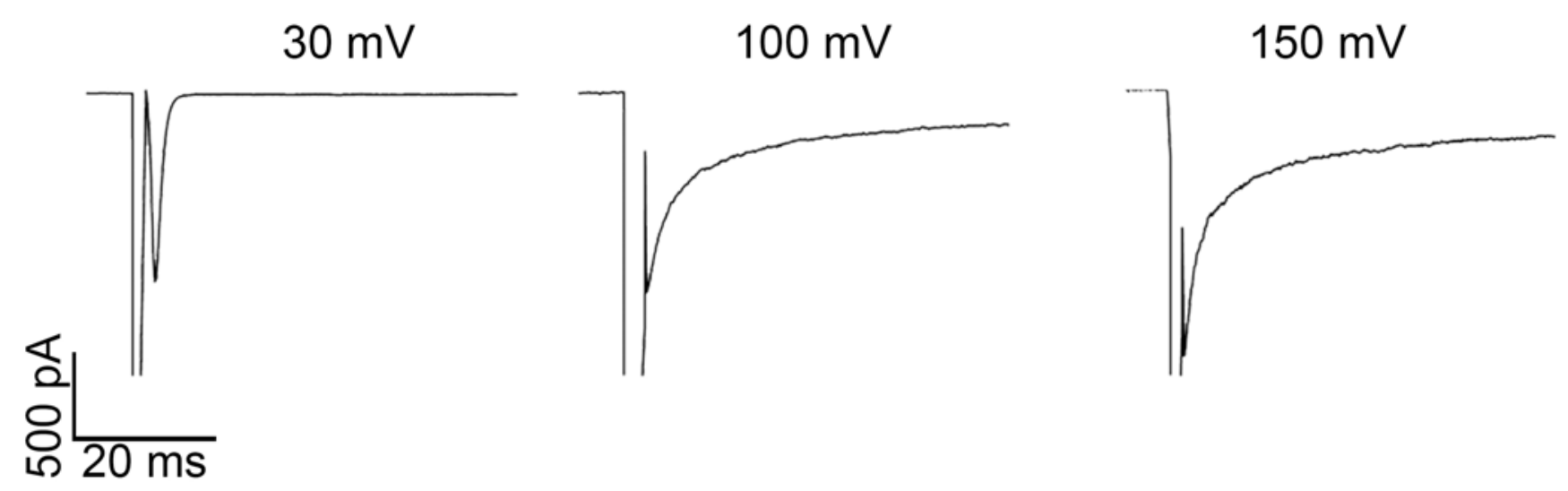

Fig. S3. Asynchronous release events are not apparent in EPSCs evoked by stimulating preganglionic input to the medulla. Representative EPSCs evoked by stimulating splanchnic input at different voltages (30,100, and $150 \mathrm{mV})$ in WT slices. 


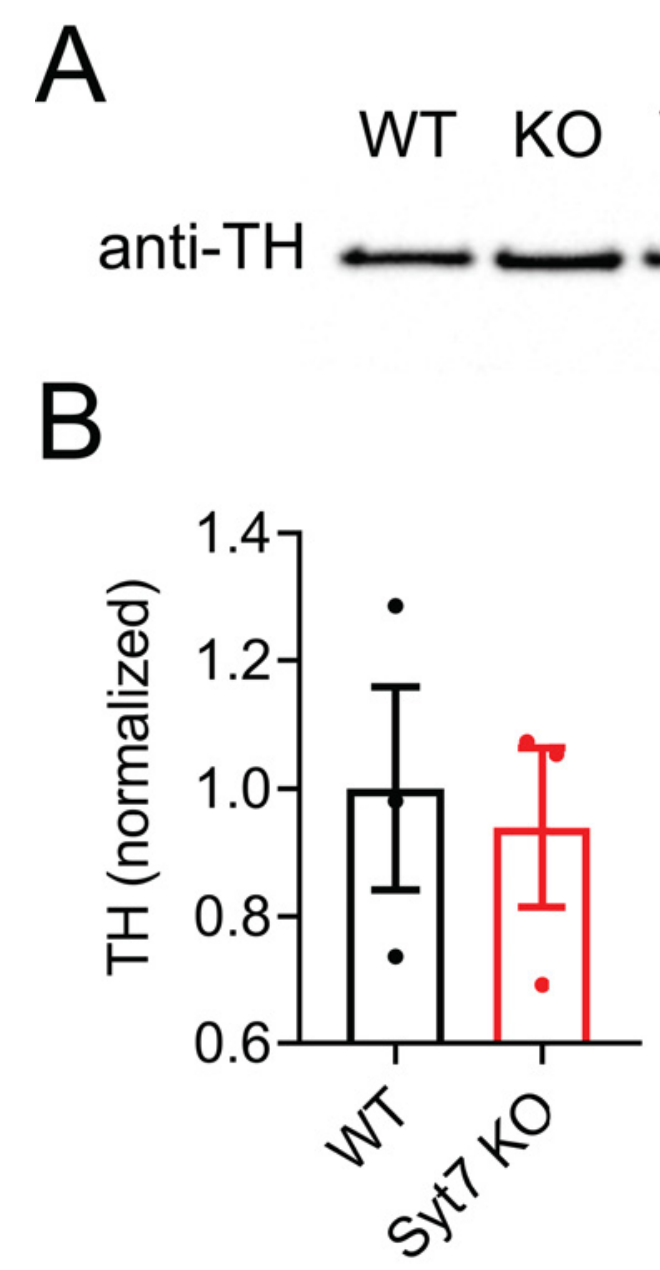

Fig. S4. Western blot analysis of TH in WT and Syt7 KO adrenal medullas. A. Medullary lysates (2 in each lane) were run on a gel, transferred to nitrocellulose, and probed with a TH antibody (immunoreactive band at $59 \mathrm{kD}$ ). B. Bands in A were normalized to protein loaded by Ponceau-S staining. No significant difference was observed in TH abundance between WT and Syt7 KO medullae. $p>0.05$, Student's t-test. 